\title{
Collection Weeding: Innovative Processes and Tools to Ease the Burden
}

Gregory M. Nelson

Brigham Young University - Provo, greg_nelson@byu.edu

Michael C. Goates

Brigham Young University, michael_goates@byu.edu

David S. Pixton

Brigham Young University - Provo, david_pixton@byu.edu

Megan Frost

Brigham Young University - Provo, megan@byu.edu

Dan Broadbent

Brigham Young University - Provo, dan_broadbent@byu.edu

Follow this and additional works at: https://scholarsarchive.byu.edu/facpub

Part of the Library and Information Science Commons

\section{Original Publication Citation}

Nelson, G. M., Goates, M. C., Pixton, D. S., Frost, M., \& Broadbent, D. (2020). Collection weeding: Innovative processes and tools to ease the burden. The Journal of Academic Librarianship, 102139.

\section{BYU ScholarsArchive Citation}

Nelson, Gregory M.; Goates, Michael C.; Pixton, David S.; Frost, Megan; and Broadbent, Dan, "Collection Weeding: Innovative Processes and Tools to Ease the Burden" (2020). Faculty Publications. 4493. https://scholarsarchive.byu.edu/facpub/4493

This Peer-Reviewed Article is brought to you for free and open access by BYU ScholarsArchive. It has been accepted for inclusion in Faculty Publications by an authorized administrator of BYU ScholarsArchive. For more information, please contact ellen_amatangelo@byu.edu. 
TITLE: Collection Weeding: Innovative Processes and Tools to Ease the Burden

\author{
AUTHORS: \\ Gregory M. Nelson ${ }^{\mathrm{a}}$ \\ Michael C. Goates ${ }^{\mathrm{a}}$ \\ David S. Pixton ${ }^{\mathrm{a}}$ \\ Megan Frost $\mathrm{t}^{\mathrm{a}}$ \\ Dan Broadbent ${ }^{\mathrm{a}}$

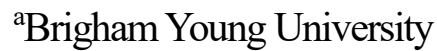 \\ 2320 HBLL \\ Provo, Utah 84602 USA

\section{Corresponding Author:} \\ Gregory M. Nelson \\ greg_nelson@byu.edu \\ Brigham Young University \\ 2320 HBLL \\ Provo, Utah 84602 USA \\ Declarations of interest: none
}

\title{
Highlights:
}

- Step-by-step review of a collection evaluation project in a large academic library

- Evidence-based evaluation criteria should be developed early in review process

- Usage statistics and other metrics are helpful, but should be used judiciously

- Project management tools help to monitor progress and improve productivity

- Innovative virtual review shelf involved professorial faculty in collection weeding

\section{Keywords:}

- Academic libraries

- Collection evaluation

- Collection management

- Deselection of library materials

- Weeding

\author{
Abbreviations \\ GIS: Geographic Information System \\ SFU: Single Facing Unit
}

\section{Funding}

This research did not receive any specific grant from funding agencies in the public, commercial, or not-forprofit sectors. 
Collection Weeding: Innovative Processes and Tools to Ease the Burden

Abstract. Evaluating collections and ultimately removing content poses a variety of difficult issues, including choosing appropriate deselection criteria, communicating with stakeholders, providing accountability, and managing the overall timetable to finish projects on time. The Science and Engineering librarians at Brigham Young University evaluated their entire print collection of over 350,000 items within one year, significantly reducing the number of items kept on the open shelves and the physical collection footprint. Keys to accomplishing this project were extensive preparation, tracking progress and accountability facilitated by Google Sheets and an interactive GIS stacks map, and stakeholder feedback facilitated by a novel web-based tool. This case study discusses guidelines to follow and pitfalls to avoid for any organization that is considering a large- or small-scale collection evaluation project.

The adage is true that there is nothing so constant as change. Libraries continually experience change to information formats, systems, processes, and community attitudes. Similarly, libraries face the constant need to evaluate library collections for current, relevant, and accurate content, especially in the science and engineering section of an academic library.

Collection evaluation, or weeding, is the process by which a librarian evaluates the library collection to determine whether individual items still merit inclusion in the collection and serve the patrons for whom they were purchased. In an academic library, a key consideration is whether the items support current research and pedagogical requirements. Sometimes the process is driven by other factors, including a need to open up space for other materials or services. Collection evaluation is an important aspect of keeping the collection vibrant and relevant to the university community. Unfortunately, weeding is also time consuming, intellectually challenging, emotionally fatiguing, and potentially alarming to library patrons. 
Brigham Young University’s (BYU) Harold B. Lee Library (HBLL) implemented a comprehensive building plan in 2017 designed to foster greater employee collaboration and workplace efficiency. As part of that plan, the library administration of the HBLL decided to consolidate the dispersed sections of the Library Information Technology (LIT) Division into one location and build a much-needed conference room. The location selected for the LIT space and the conference room displaced $37 \%$ of the overall science and engineering print collection footprint, including 948 "single facing units" or SFUs — consisting of seven shelves on a 35-inch-wide bookcase (see Figure 1) - out of the total of 2,654 SFUs in the science and engineering collection area. Members of the Science and Engineering Department were asked to complete a collection evaluation project in which their entire collection, over 350,000 print items on 18,578 shelves, was evaluated. A weeding project of this scale had not been done in the library within the memory of current employees.

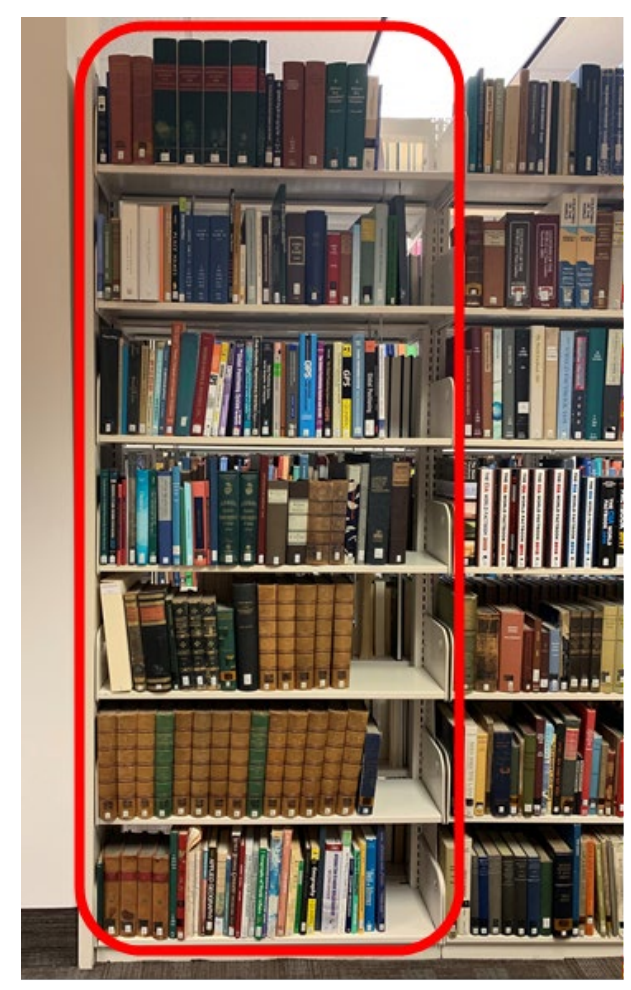

Figure 1. Single-facing unit (SFU)

In addition to the need to vacate shelves to provide space for the building project, there were other reasons that made reviewing the collection beneficial. Anecdotal stories referred to an earlier period of less discriminative 
collecting where some items were added that, in a more needs-driven collecting climate, are ripe for weeding. In the end, this mandated collection evaluation project became an opportunity to review all of the print materials in the science and engineering collection and determine if those materials supported the mission and direction of the library and the university.

\section{Literature Review}

Weeding projects are important and complex tasks in libraries. The literature describes many aspects involved in successfully planning and carrying out weeding projects. Weeding is helpful to libraries because it reduces the number of books needed to be stored and maintained. It allows "librarians to become familiar with the depth, breadth, and currency of the collection" (Soma \& Sjoberg, 2010, p. 19). It benefits patrons by making items easier to find (Dilevko \& Gottlieb, 2003). Additionally, weeding frees up space for new materials and for space needed for other purposes such as collaborative study space, information commons, teaching and learning centers, and cafés (Lugg, 2012).

Lack of time is cited as the main impediment to an active weeding process (Dilevko \& Gottlieb, 2003), where the time burden may include several months just for planning and multiple years to complete the evaluation process (Crosetto, Kinner, \& Duhon, 2008, p. 30). Crosetto et al. (2008) reported that their initial goal was to review one million volumes within two years, but at the end of the two years, they had completed only $20 \%$. They estimated that to review all volumes would take a total of seven years or more. Soma and Sjoberg (2010, p. 19) reviewed their collection of approximately 300,000 volumes and estimated it would take three to five years to weed $15 \%$ of their collection using circulation data alone. Their long-term plan, which would allow for a thorough review of the entire collection, was estimated to take 8 to 12 years. Dubicki (2008) reported their project took two years to review 72,500 books, identifying 12,800 for removal.

Identifying stakeholders and having a clear plan of how to involve them is necessary for successful weeding projects. Stakeholders in an academic library setting include library administrators, library faculty and staff, 
professorial faculty, students, and some university administrators (Ward, 2015, p. 18). Professorial faculty, in particular, are critical stakeholders and a common theme in the literature is the delicate nature of how to involve them. Crosetto et al. (2008, p. 44) pragmatically described how involving these faculty not only gives them "a sense of ownership, but involving them from the outset can also prevent future friction over decisions made about the collection." Busch, Nance, and Teague (2018, p. 7) described positive results derived from complementing the skills of the librarian with the domain-specific knowledge of the professorial faculty.

When balancing the consideration to involve faculty, DeMars, Roll, and Phillips (2019, p. 33) noted that extensive involvement of faculty delayed the project considerably, by as much as a factor of three. It is worth noting that not all stakeholders care deeply about weeding projects (Metz \& Gray, 2005, p. 274). Additionally, those charged with carrying out a weeding project should expect that issues will arise but that they will resolve themselves with time (Metz \& Gray, 2005).

Timely and effective public relations efforts provide clarity and transparency to stakeholders. A common concern addressed in the literature is the need "to convince librarians, as well as university administrators and faculty, that the contents of the collection would be improved if some materials were withdrawn" (Dubicki, 2008, p. 132). Specifically, weeding removes outdated or irrelevant material, thereby keeping the collection "vibrant, relevant, effective, and accurate" and improving discoverability of the remaining materials (Ward, 2015, p. 47). Indeed, weeding projects are "one of the most politically charged activities" undertaken by libraries (Crosetto et al., 2008 , p. 44) and are stressful on library employees. Some of the stress also comes from community member complaints as well as librarians' discomfort in making the decision to remove materials and the worry of making mistakes (O’Neill, 2016).

Many weeding projects begin evaluating items based on quantitative data, including publication date, usage statistics (checkouts and in-library uses if possible), last use date, and number of copies in other libraries in the same state and across the country. While these data points can provide a first cut at the large task, other factors should be 
considered as well. A more comprehensive approach also must include the physical condition of materials, currency of content, duplication, curricular integration, appropriateness to the collection, bias, and obsolete formats (Baumbach \& Miller, 2006). McHale, Egger-Sider, Fluk, and Ovadia (2017, p. 92) identified the balance needed between "objective rules and professional judgment" and described using an integrated library system (ILS) to make initial discard lists. Librarians were then involved, making final decisions using information from WorldCat, Amazon, and Wikipedia as well as input from non-library faculty. Crosetto et al. (2008) described a similar approach beginning with ILS-generated data and then relying on subject selectors to create their own final criteria. Those criteria were supposed to be developed with input from the teaching departments, but the article noted that these efforts were not as successful as had been hoped.

Different disciplines require different criteria. McAllister and Scherlen (2017, p. 76) noted that using quantitative criteria can be effective with "disciplines such as in the sciences, that are more reliant on current materials," while qualitative criteria may be needed "for disciplines such as in the humanities, whose scholars benefit from ready access to older and low-use books." Machine learning may be helpful in reducing time requirements and stress on librarians. Wagstaff and Liu (2018, p. 246) described using data from a previously completed weeding project to train machine learning models and concluded that "models will not replace human processing, but they can instead provide an initial assessment of the list of candidates, which allows librarians to focus their time and attention on those items most likely to be weeded."

Training at the beginning of a project and interspersed periodically throughout a project can help with overall results as well as decrease the negative effects on library employees (O’Neill, 2016). It can also be helpful to create a multi-staged project plan with periodic reviews that provide for timely assessment and adjustments. A key stage in this plan could be a pilot project that informs the comprehensive plan (Soma \& Sjoberg, 2010, p. 22).

In describing how to coordinate with professorial faculty, Busch et al. (2018) described using spreadsheets that were grouped by Library of Congress (LC) call number to create smaller sets of titles that more directly related 
to specific faculty areas. DeMars et al. (2019) noted that they augmented their use of spreadsheets with the creation of an online application that was intended to streamline the process. However, it had to be modified to prevent faculty from "arbitrarily voting to retain every book" (p. 29). Forming productive relationships between library employees and professorial faculty can improve political situations and yield better results (Busch et al., 2018). While involving external faculty is helpful, how they are involved is key. Time constraints of professorial faculty are a consideration; focusing and properly limiting the scope and duration of requests on faculty can help the project stay on schedule (Soma \& Sjoberg, 2010).

This paper expands on the existing literature in three areas: developing unique project management tools, involving professorial faculty with an innovative "virtual review shelf, and documenting various practical issues impacting the execution of the project. Each of these areas is discussed in context of the overall collection evaluation project in three broad areas: preparation, implementation, and feedback. Preparation will focus on project organization and planning with particular focus on the planning team and will discuss considerations relating to developing selection criteria. Implementation will focus on the process and tools used for evaluating the collection, including tracking and accountability. Feedback will focus on how stakeholder input was sought and used. Finally, the paper will conclude with a discussion on the benefits achieved and disadvantages identified from the project.

\section{Methods}

\section{Preparation}

The planning team. Many people were necessarily involved in the organization and planning of the project due to its magnitude and potential impact on other areas of the library. The HBLL Collection Development Coordinator assembled individuals in the library who would be essential for the project's smooth implementation and completion. Appendix A describes the job titles and roles of individuals on the planning team. This team was invited to an initial meeting to brainstorm how the overall project should be organized, managed, tracked, and then communicated to the library and the university as a whole. 
Every two weeks for the first six weeks following the brainstorming session, the Collection Development Coordinator called meetings to determine the scope, needs, and timing of the project. Meeting topics included how to resolve conflicts when disagreements arose about which materials should be kept or withdrawn, how to smooth the path for employees to efficiently complete the project, how much funding would be needed to hire additional student employees in key areas, what hardware or software support would be required, how to communicate with professorial faculty as well as library personnel about the project, and how to estimate the final cost of the project. After the initial organizational stage, ad hoc meetings were held to solve immediate problems and concerns.

Since this was the first major collection evaluation project in recent memory, we tracked project expenses to assist in cost estimates for future projects. The amount of time devoted to the project, beyond an employee's normal day-to-day responsibilities, was tracked, and the cost was estimated by multiplying the number of hours spent on the project by the employee's estimated hourly wage. The following activities are representative of those that were tracked: duration of meetings held related to the project, who attended the meetings, hours spent by cataloging personnel to change item records, time spent by personnel in the onsite storage area for processing item records and relocating physical items within the onsite storage area, subject selector hours spent on generating criteria for evaluation and the associated manual review process, and the creation and support of specialized software. Additionally, costs were tracked for software to assist in collection visualization and wages for student shelvers who tagged and moved materials between the open stacks, the staging area, and onsite storage.

The planning team developed a rough timeline with estimates that were occasionally reevaluated and adjusted for accuracy and feasibility. The planning phase took about 2.5 months; the evaluation phase was originally set for seven months, but ultimately was extended to 12 months. The feedback phase of the project lasted for two months and allowed library employees, professorial faculty, and university staff to provide feedback on materials proposed for deselection. 
Review criteria. The planning team defined three possible outcomes for library materials under review: items could be selected for withdrawal from the library (deselected); they could be removed from physically browsable shelving and placed in onsite storage; or they could be kept on the shelves in the open stacks. While choosing the onsite storage option would make access to those items somewhat less convenient, they would remain electronically discoverable and readily retrievable. It is possible that all items removed from the browsable shelving could have been accommodated by this storage option, thereby eliminating the more difficult decision to withdraw materials. However, this option was not viewed as sustainable in the longer term due to space and practical collection management limitations; furthermore, this project provided an opportunity to strengthen the collection by removing material that did not support the mission of the library. Thus, the department elected to engage in a true "weeding" effort.

In order to determine which of the outcomes should apply, each item in the targeted collections was evaluated against a set of review criteria. Consistent with the logic of Crosetto et al. (2008) and McAllister and Scherlen (2017) these criteria were subject-specific, which allowed for customization to cater to the unique needs of each academic program supported by the collection (Zuber, 2012). Each subject selector was responsible for creating criteria for each area of departmental responsibility. While the review criteria were thus customized by discipline, the different criteria sets established by individual librarians had general similarities. For example, all sets of criteria valued resource usage information, generally keeping items on the shelf that were used a modest number of times and within a recent time frame. Similarly, the age of the item, as determined by the publication date, was considered a salient consideration for most science and technology areas, with preference given to works representing more current states of knowledge as opposed to older, possibly outdated technology and theory. Finally, access to the various works was considered: in general, we did not remove anything from the collection that was rare or difficult to find. Holdings at other US libraries, online archives in trusted locations, and duplicates or similar editions held at the HBLL were generally regarded as suitable options for satisfying access considerations. 
These objective criteria facilitated preliminary screening of library materials, which was a large time saver since electronic means could be used confidently without much human intervention. ${ }^{1}$ More detailed information relating to these criteria, including specific threshold values used for screening materials for withdrawal or onsite storage, is found in Appendix B and Appendix C, respectively. It should be noted that, along with differences in specific age, usage, and access criteria, there were also differences in how the various considerations were combined and applied. These differences are also recorded in Appendix B and Appendix C.

As has been described previously in the literature (e.g., McHale et al., 2017), successful weeding projects in the past have employed a mix of objective rules and human judgment. Such was the case for this project. Thus, in addition to the more concrete criteria just mentioned, we also subjected screened materials to further evaluation using "soff" factors that were based on the subject selector's experience and knowledge of the programs served. We note here that where the concrete factors were typically set prior to the implementation phase, the soft factors were often formalized during the process of implementation as various circumstances were encountered. These soft factors are described more fully in the next section.

\section{Implementation}

A multi-stage filtering process. An electronic tool, GreenGlass ${ }^{\oplus 2}$, was used for the initial screening step defined above. This tool ingests collection data recorded by the HBLL (including usage information) and aggregates it with holdings information obtained from other institutions (from the WorldCat ${ }^{\circledR 3}$ database). This allows age and usage records to be placed in context with global access data to better inform the screening process. This aggregated information was filtered according to the criteria mentioned above to create lists of library materials that are candidates for removal from browsable shelving.

\footnotetext{
1 At times, objective criteria missed some candidates for withdrawal, such as multiple editions of a book which met total usage criteria. However, missing such items erred on the side of conservatism and had little material impact on the overall results.

2 GreenGlass is a registered trademark of Online Computer Library Center, dba OCLC

3 WorldCat is a registered trademark of Online Computer Library Center, dba OCLC.
} 
Those items that met the established usage, age, and access criteria for deselection were marked and then subjected to experience-based review, first by subject selectors, and later by professorial faculty who desired to participate in the review. The effect of this experience-based review was to further reduce the body of materials slated for deselection or storage by considering other value factors besides age, usage, and access. The soft criteria used during this step included whether works were seminal, contained unique or historical information, or added specific value to the local community. In certain cases, whole subject areas were heavily marked for deselection based on the initial screening criteria - the subject selectors made judgments in these cases as to whether heavy losses in a given area were appropriate (e.g., a discontinued program), or whether representative material ought to be kept to ensure proper breadth of the collection. At this stage of the project, subject selectors also looked for further evidence of usage to supplement the data from which the initial screening lists were derived. This additional evidence included records of onsite usage and stamps in the book's due date register that perhaps were not recorded in the data used for screening. Finally, the physical condition of the materials was considered; this was particularly useful when choosing between multiple alternatives to the same work. Appendix D contains details of the soft criteria used following the preliminary screening process.

The authors note here that the experience-based review was not strictly limited to those items that were tagged during the initial screening process. Other untagged items were occasionally reviewed at this state, including duplicates, multiple editions of the same book, and series of books (see Appendix D).

A final filtering process took place following the subject selectors' review. At this stage, the professorial faculty and other library faculty were invited to review the body of materials being considered for withdrawal, voting to keep items that should be retained based on their research and teaching needs.

Project management tools. In order to complete the review of the collections in the required time period, several project management tools were put into place during the beginning stages of the process. While some trial 
and error took place early on, we found and developed a number of tools that helped to effectively manage the workload, communicate with other individuals involved, and track progress.

On-shelf review tools. Using spreadsheets that contained the GreenGlass ${ }^{\circledR}$ report data, selectors determined a projected outcome for each book within the collection. These spreadsheets were given to student employees who used the data to tag each book slated to be removed from browsing shelves with a strip of painter's tape (Figure 2). We found painter's tape to be an effective tool for tagging the books because it adheres well to a variety of book bindings, and in almost all cases, it could be easily removed without leaving a residue or harming the binding. The color of the tape used on each book corresponded with the projected disposition of each book. Books to be withdrawn from the collection were tagged with purple tape, those that were to be moved to an onsite storage area were tagged in yellow, while those intended to remain on the shelf received no tag.

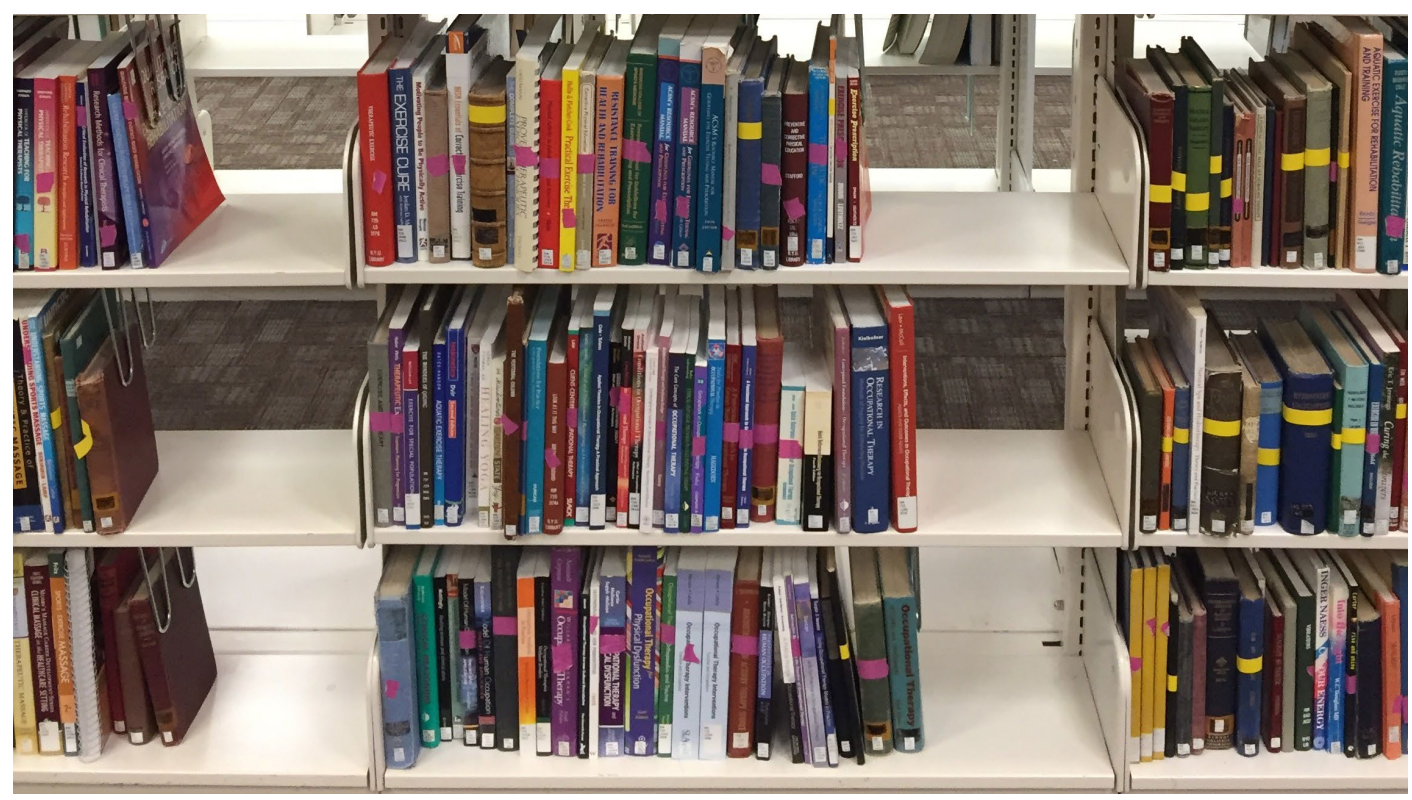

Figure 2. Books marked with painter's tape

The decision to put no tags on the books that were intended to remain in the open stacks was intentional.

During the process, if a tag fell off or was removed by a patron, the book remained on the shelf. Although this likely resulted in the library keeping a few books that were intend to be withdrawn, it prevented books intended to be kept from being withdrawn accidentally. 
Selectors collectively chose to keep any book in the open stacks that was used by patrons during the collection evaluation process, even if it had already been tagged for removal. If a tagged book was checked out or removed from a shelf by a patron during this period, the tape was simply removed by a library employee before reshelving the book.

Once all the books within a specified call number range were tagged by shelvers, subject selectors then moved through the stacks, reviewing each tagged item. Using the experience-based criteria that each selector developed, selectors removed (and occasionally added) tags where necessary. Selectors then placed green and red laminated sheets into the shelves to bookend the books reviewed each day (shown in Figure 3). These sheets indicated to shelvers that the enclosed tagged books were ready to be removed from the shelf. This tool was implemented to expedite the review process as it enabled both shelvers and selectors to work asynchronously and optimize their own schedules.

We found small rolling desks (shown in Figure 4) to be an effective tool for shelvers when tagging the books and for selectors when reviewing the books. Lists, computers, and tape easily fit on the desk as well as books that were not easily cradled by hand. The desk model we used fit comfortably in between the shelves and could be easily raised and lowered when reviewing high and low shelves. 


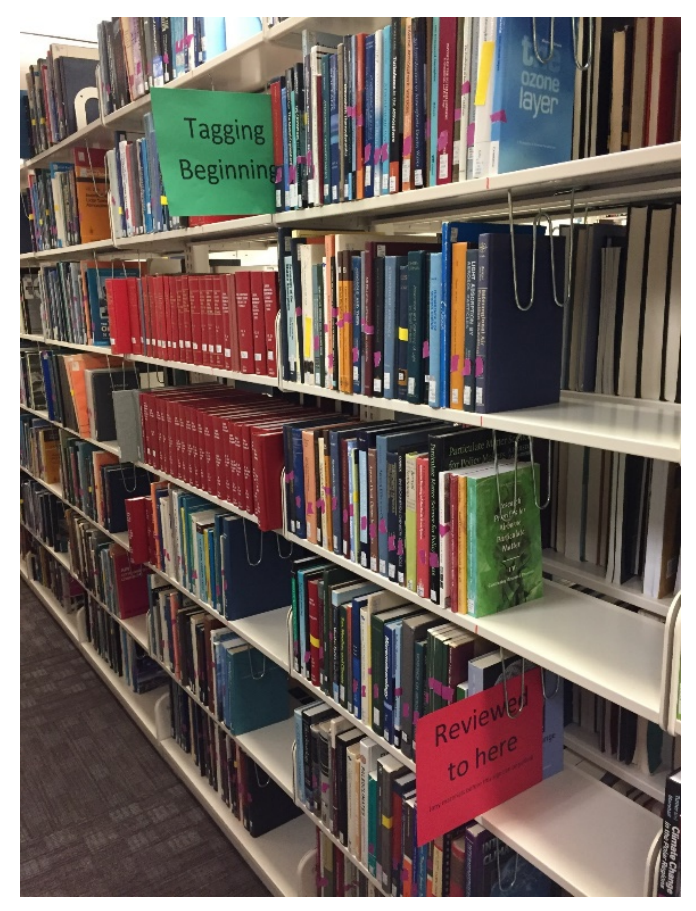

Figure 3. Green and red tagging bookends

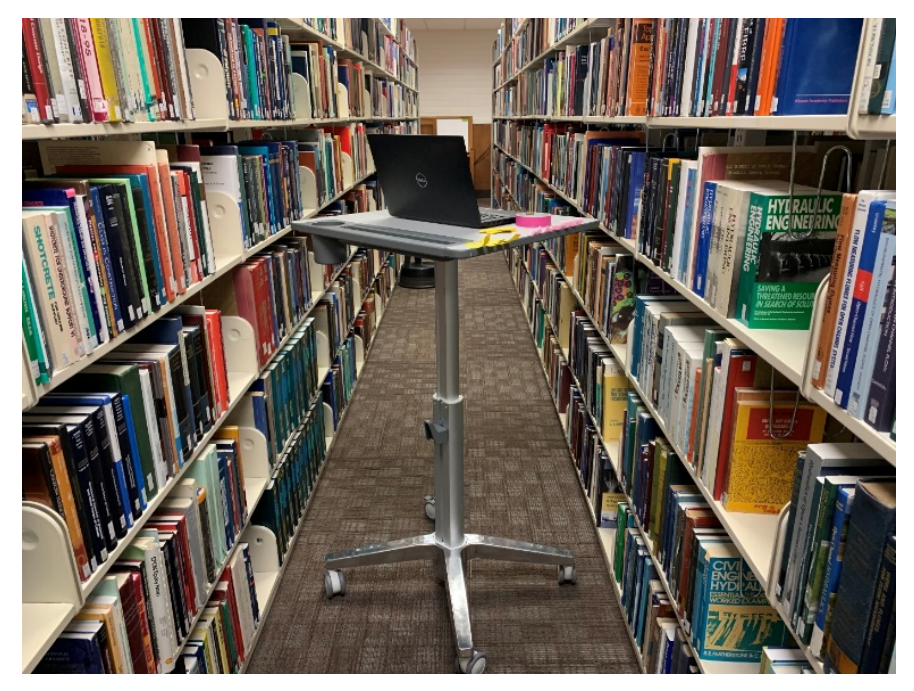

Figure 4. Rolling desk

Tracking and accountability. Using Google Sheets (https://docs.google.com/spreadsheets/), selectors developed a tracking and accountability form to record the progress of the project. We found that recording the number of books reviewed each day was a more complicated endeavor than expected, largely due to the variable nature of how serials in our library have been cataloged and counted. An easier and clearer indicator of progress was 
to record the number of SFUs we reviewed each day and compare it to the total number of SFUs that still needed to be reviewed. In addition to the tracking and accountability form, individual selectors also kept track of the total number of hours spent on the project. The department met weekly to discuss both progress and challenges as they arose during the process.

A unique and valuable tool created by the Geospatial Librarian at Brigham Young University was an interactive map using the software tool $\operatorname{ArcGIS}{ }^{4}{ }^{4}$ to visually track the progress. The map used an aerial photo of the library with an overlay of the science and engineering collection shelves. The shelves were divided into individual SFUs and marked with their corresponding Library of Congress subclasses (see Figure 5). The map enabled selectors to highlight each SFU individually and change its color to indicate that review of the shelves had been completed. The program then automatically recalculated the number of reviewed and non-reviewed SFUs in each call number. This tool allowed not only subject selectors to easily view progress, but it also was a useful tool for reporting progress to the library administration and other library employees involved in the project.

\section{Feedback}

${ }^{4}$ ARCGIS is a registered trademark of Environmental Systems Research Institute, Inc (ESRI) 
Feedback from professorial faculty was gathered during the project through conversations, email exchanges, and a voting process that will be described later. Comments from professorial faculty and library employees were also gathered after the project was completed through individual interviews.

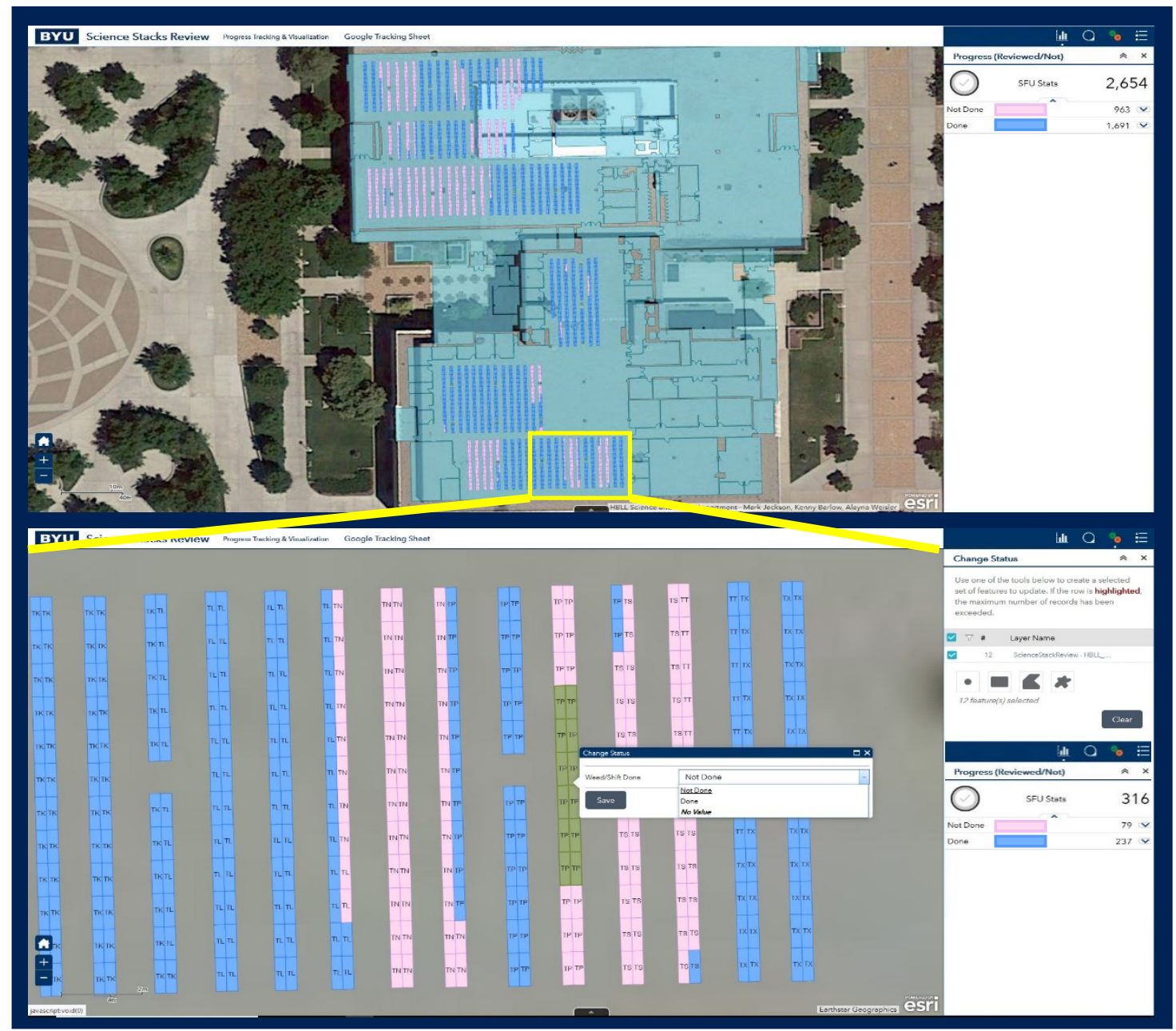

Figure 5. GIS mapping of stacks and tracking

Involving professorial faculty. It was important that professorial faculty were involved so that their unique perspectives on books and authors, as well as the important topics for their teaching and research, could be considered. However, determining how to involve faculty, including the level and frequency of involvement, was a delicate balance as has been described in the literature review.

Near the beginning of the project, all campus faculty were notified via an emailed memorandum from the University Librarian (Dean) that a collection evaluation was ongoing. The memo stated that (a) print materials 
would be carefully examined for relevance to curricular and research needs, (b) faculty in affected disciplines would be contacted, and (c) the desired outcome of the effort was to have a strong collection and spaces that met campus needs better. After the science and engineering subject selectors completed their review, subject selectors contacted their professorial faculty from the affected departments and asked them to review those books that had been marked for removal. Professorial faculty were given a period of two months to accomplish this review.

Voting tools: Spreadsheets and "virtual review shelf." One potential method of involving professorial faculty was to provide a spreadsheet listing the books selected for removal and listed in LC classification order similar to Busch (2018). Sharing the entire spreadsheet with faculty was unappealing because its size —over 150,000 items - made it unwieldy to navigate. The list could have been broken up into LC groupings that related to specific departments; however, the faculty might have potentially missed important cross-disciplinary items that were cataloged in a different LC area. Given these considerations, this option would have created a large barrier to patron participation.

A better way to obtain feedback and general review of our decisions from the faculty was to utilize a familiar tool — the library search portal. A virtual review shelf(VRS) tool was developed and embedded into the library's native discovery system so faculty could, in a familiar environment, conduct a focused search for items marked for removal related to their teaching and research. Faculty members could vote to keep any item from their search and add comments explaining their rationale (Figure 6). To vote, faculty members had to log in to their personal account within the library website, which identified them, their department, and their comments for each item that they voted to keep. In all, 108 individuals from 43 different departments and organizations in the university participated in the voting phase of the project. They voted to keep 3,534 items that had been marked for removal; with the exception of a few titles that had editions that were more current on the shelf (which the faculty had not noticed), all were kept based on these recommendations. 


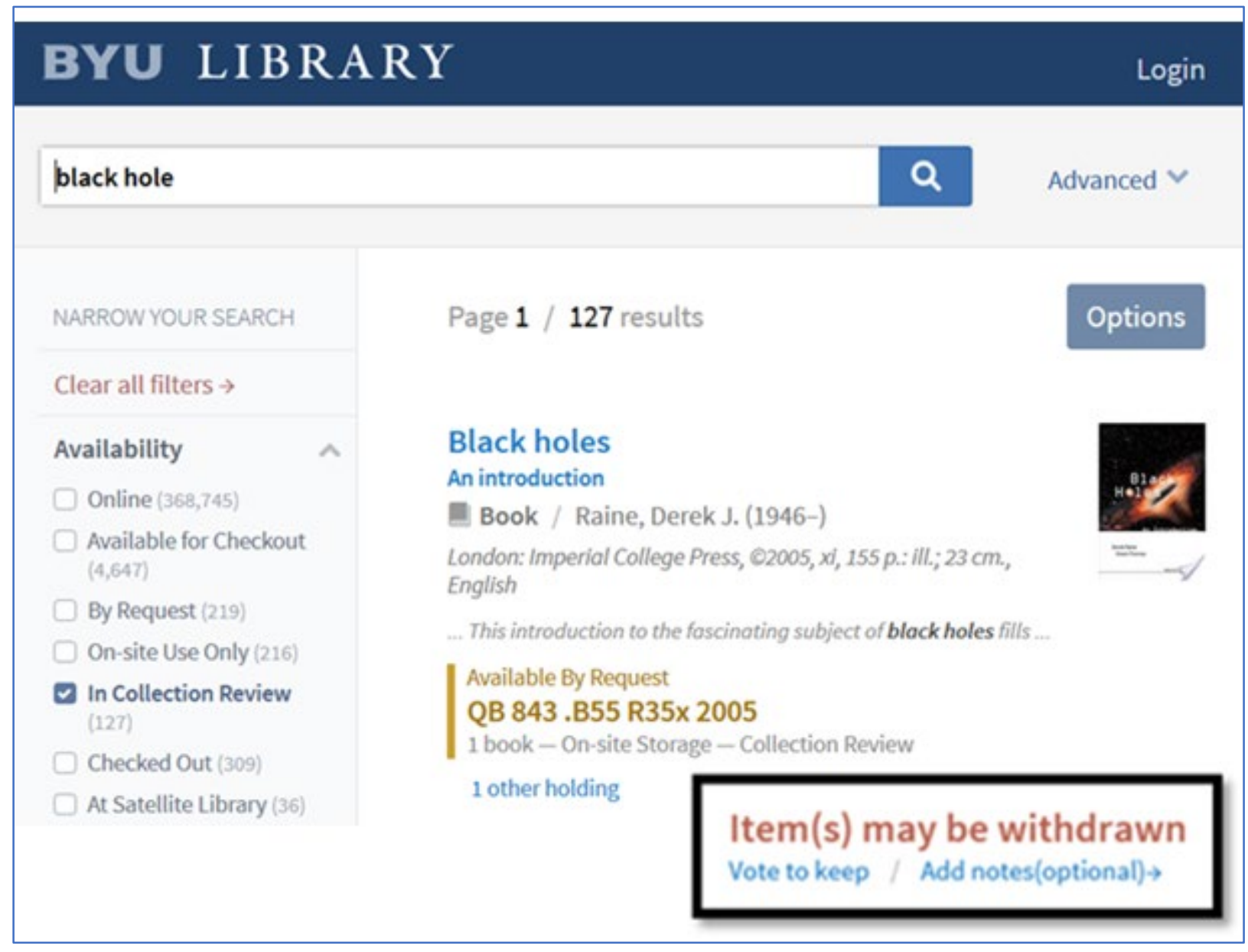

Figure 6. Voting function in the virtual review shelf

In-depth interviews. To capture the perspectives of, and lessons learned by, the varied library personnel involved in the project, interviews were conducted with 20 library employees. A newly appointed librarian to the Science and Engineering Department, who was not involved in the evaluation process, served as the interviewer in order to encourage candid assessment of the project. The results of these interviews, along with in-depth interviews obtained from professorial faculty that participated in the project, will be reported in a future paper.

\section{Discussion}

Overall, this large-scale collection evaluation process was a successful undertaking, as measured by achievement of organizational objectives mentioned at the outset. Table 1 summarizes the results and costs of this endeavor. 
Table 1. Project Statistics

\begin{tabular}{|l|c|}
\hline Items withdrawn from collection & 189,250 \\
\hline Items sent to onsite storage & 52,761 \\
\hline SFUs removed (incl. shelf reconsolidation) & 1,616 \\
\hline Hours spent by subject selectors & 1,633 \\
\hline
\end{tabular}

As is to be expected with a project of this magnitude, not all of the plans worked out as predicted and some process modifications were made along the way. Some of the more important lessons learned are discussed below. The authors present these for the potential benefit of any library that might be considering a similar project.

\section{What Worked Well}

Quite possibly the most critical aspects of this collection evaluation were the development and execution of a thorough planning process. This included our communication and collaboration plans. During this project, one area to which we paid particular attention was identifying and including all stakeholders in the evaluation process. Within the library, interested parties included subject selectors outside of the science and engineering disciplines (e.g., area studies, psychology, etc.), cataloging, acquisitions, and stacks management, to name a few. These stakeholders each brought unique perspectives and helped us to anticipate potential challenges and to develop workable solutions throughout the entire project.

Another important aspect of the planning process was developing solid evidence-based criteria. Each subject selector was able to modify these criteria to meet specific needs for a given subject area, often through an iterative process. These criteria were extremely helpful throughout the evaluation process by allowing subject selectors to critically evaluate large numbers of materials in a reasonable amount of time.

An invaluable tool in the planning process was the ability to consolidate the usage statistics for our library materials with OCLC holdings records using the GreenGlass ${ }^{\circledR}$ software. The GreenGlass lists were particularly valuable in helping us to test and visualize deselection criteria. 
The patron virtual review shelf was another extremely helpful tool to allow interested university faculty and staff the ability to provide feedback on items proposed for deselection. While not without challenges, this tool provided a much easier way to collect external feedback in a manner that was familiar to library patrons. The success of the VRS was due to a collaboration with the library's Information Technology Division. We communicated that we wanted something easy to search, add or remove a personal vote, and share comments. Creating a facet in the existing ILS that selected only items that had been identified for withdrawal seemed like the easiest, most straightforward and cost-effective option available. Several iterations were implemented with consistent feedback from the science and engineering librarians until we had a tool that we were comfortable with and that would provide us with solid data for the items that faculty felt should be kept. This part of the weeding project provided the secondary benefit of creating additional opportunities to interact with faculty members on a project important to them.

During the physical review of the print materials, there were several tools that greatly increased the productivity and ease of the review process. First, enlisting student employees to tag proposed items for deselection and onsite storage before having the subject selectors review these materials in the stacks was an overall cost saver and an enormous timesaver for the library faculty. The subject selectors still generated the lists that were used by the student employees to tag these items, but having the physical tagging done by students allowed the subject selectors to focus on other aspects of the project while materials were being tagged. After the tagging process was completed, subject selectors were then able to review tagged items in the stacks to make any final adjustments before materials were removed from the shelves. Student employees also removed items from the shelves following the final subject selector review. The green and red laminated sheets were also very helpful to allow subject selectors and student employees to work simultaneously in adjacent collection areas, thus greatly speeding up the overall review time. For the subject selectors, the height-adjustable personal rolling tables were surprisingly helpful and made the in-stack review substantially more comfortable. Lastly, the online tracking tools (both the Google Sheet and the GIS 
interactive map) were also extremely helpful to keep subject selectors motivated and to accurately track the overall progress of the project.

\section{Challenges}

Despite the overall positive outcomes from this collection evaluation project, there were some challenges that we encountered at various stages of the process that are worth noting for those who might be undertaking a similar evaluation project. Some of these challenges were unavoidable, while others were a result of human error. Similarly, some were easily remedied while others required significant effort to resolve. In some instances, challenges could not be alleviated and we had to make do with whatever limitations already existed. In the following sections, we will discuss specific challenges we faced and include suggestions on avoiding potential pitfalls and overcoming obstacles that do arise.

Limitations of analytical data. Some of the larger challenges that we encountered related to the data sources we used to analyze our collections. Several challenges in particular related to our own ILS. Some items had exaggerated usage statistics due to internal checkouts (e.g., items needing repair would be checked out to the library's book repair unit or items on display shelves would be checked out to a pseudo-patron created specifically for the display shelf). These internal checkouts counted toward the total circulation statistics, artificially inflating actual patron use and demand. For our project, we were not able to remove these internal usage counts from the overall circulation statistics for our collections. However, the impact of internal uses was likely rather small when compared to the overall project, as only a small percentage of items would receive internal checkouts. As the only likely possible impact of internal checkouts would be to retain more items in our collections that otherwise would have been withdrawn, we felt comfortable accepting these limitations.

A second challenge with our ILS usage information was related to in-library uses. Our ILS accommodates recording both in-library uses and checkouts separately, including the date of the last event in each category. However, when uploading our data into GreenGlass ${ }^{\circledR}$, only one date was captured. We thus had to determine which 
date was to be used - and favored the checkout date. While the date of last in-house use would have been informative for our project, this information was not available in the consolidated data. Some librarians used a separate report to add visibility to this type of usage. For future collection evaluation projects, it may be worthwhile to consider adding this metric to current ILS tracking protocol to allow for a more complete picture of collection usage.

Another issue we observed related specifically with changing ILS platforms. When our library migrated to a new ILS platform in 1998, all previous circulation information (both in-library use and checkout history) was deleted from our records. Since we had nearly two decades' worth of circulation statistics after changing ILS platforms, we did not view this as a major problem. However, if a library wished to consider all historical use of an item or if ILS migration happened more recently without ingesting previous circulation information, this could represent a substantial challenge to any evaluation project. Libraries should carefully consider how any ILS changes may impact future evaluation projects and explore the possibility of filtering such data prior to sending it to GreenGlass.

GreenGlass was a very helpful tool to consolidate all of our collections, circulation statistics, and OCLC worldwide library holdings into one easy to use platform. However, the information contained in GreenGlass represented a snapshot in time and was not updated with new circulation or OCLC holdings information. After GreenGlass ingested our circulation information, any subsequent checkouts or in-library uses were not reflected in the reports we used to make collection decisions. We understood this limitation at the beginning of our project and determined to evaluate our collections as quickly as possible to maintain a high level of accuracy of the circulation information. In addition, as subject selectors were reviewing physical materials in the stacks, they would often consult the back of the book where checkout date stamp records were maintained. On occasion, particularly as the project went on, subject selectors would discover items with checkout date stamps after the GreenGlass ${ }^{\circledR}$ ingestion date and would elect to keep these items in our collections rather than removing them from the library. Any library 
planning on using GreenGlass or a similar product should carefully schedule the timeframe of their project to allow collection retention decisions to be made as quickly as possible after their circulation information is ingested as part of this tool.

On the ground. In addition to some of the analytical data, we also experienced some minor logistical challenges during the physical review of materials. Early on, it became apparent that there was substantial overlap between subject selectors in a few specific call number ranges. To account for multiple interests in these areas, we assigned one subject selector as the primary reviewer and then listed any subsequent selector as a secondary reviewer. The primary reviewer generated the GreenGlass tagging report for the call number range and conducted the initial physical review of tagged materials. After the primary reviewer finished examining the tagged materials and made any desired changes, the secondary reviewers would then go through these call number ranges and remove additional tags for items they felt should remain in the library collections. Overall, this worked rather smoothly, but it did require close coordination to ensure every interested subject selector had the opportunity to review these materials before they were removed from the stacks.

One of the more substantial logistical challenges occurred due to inconsistencies in the tagging process of materials proposed for deselection or transfer to onsite storage. Our student employees generally did a wonderful job tagging these materials based on the preliminary screening reports created by subject selectors. However, with a project of this size, human error is inevitable and there were several instances where books were erroneously tagged for withdrawal or onsite storage. In some instances, it appeared that taggers inadvertently shifted one line of the deselect spreadsheets, resulting in multiple errors in a smaller call number range. More frequently, these errors were the result of adjacent books being tagged to the actual item on the list. We attribute most of these errors to fatigue, as the tagging lists were quite large and the process of tagging books was rather tedious. The subject selectors were able to overcome these challenges during the physical review of tagged items. Indeed, one of the primary reasons for the physical review of materials in the stacks was to make sure that these materials were tagged correctly. 
A less common logistical challenge occurred when tagged materials were removed from the circulating shelves before the subject selectors were able to complete their physical review. This only occurred once or twice throughout the entire project, but it did require special coordination to resolve. Fortunately, the unreviewed items were discovered early on and were quickly located in the onsite storage staging area. The subject selectors were then able to review these items in the staging area and return any desired materials to the circulating stacks. This was a rare challenge largely due to the success of the green and red laminated sheets that easily and clearly communicated the status of the physical review process between the subject selectors and the student shelvers. However, this does point to the utility of planning in a delay between initial disposition and final action (i.e., permanently disposing of books).

Serials. Throughout the collection review process, serial publications proved to be much more problematic than monographic publications and required careful consideration. The first of these challenges related to the ability to track the actual number of volumes within our circulating serial collections. Some serials were analyzed to the monographic level for each individual volume, while others were contained on a single bibliographic record. Others were split between multiple bibliographic records due to title name changes or other less obvious reasons. Still others were only partially analyzed and cataloged as monographs while all remaining volumes of this same serial publication were represented in a single record. This resulted in disjointed collection decisions for a single serial publication. For example, GreenGlass ${ }^{\circledR}$ was only able to capture information for monographs or serials analyzed at the monographic level. Consequently, partially analyzed serial publications would erratically show up as monographs in our screening reports and would be assessed independently of the rest of the non-analyzed volumes within this same serial title. For the subject selectors, this would only become apparent after the student employees had completed the initial tagging of materials proposed for deselection or onsite storage. This was mitigated during the physical review of tagged materials by removing the tags from any individual volumes that were tagged for a different outcome than the rest of the serial run. 
Another challenge that we encountered with serial publications related to the reliability of usage statistics. Our internally gathered usage statistics for non-analyzed circulating serials did not accurately represent actual usage, particularly for in-library uses. To account for these challenges, we evaluated our serial publications using a separate system from that used with our monographic collections. We generated a complete list of all circulating serial publications within the specific call number ranges impacted by this project and then recorded the total number of other libraries owning print copies of this same publication. Subject selectors then based collection decisions primarily on relevance to current curricular and research interests as well as availability at other institutions.

One logistical challenge with serials that is not problematic for monographs is the inability to split a serial run between two different locations. Due to the inability to account for non-analyzed volumes that do not reside in the same location as the parent record, subject selectors were restricted from moving some volumes of a series to storage while retaining the remainder in the browsable shelves.

Active serial subscriptions also posed some logistical challenges for the evaluation project, particularly for those serials with irregular publication schedules. Oftentimes, subject selectors would make a decision to withdraw a serial publication or move it to onsite storage without realizing that the library still maintained an active subscription. This sometimes led to violation of the restriction just mentioned by inadvertently splitting the location of a serial between onsite storage and the browsable shelves. In addition, for those serials that were completely withdrawn, subject selectors most often did not have a desire to receive future issues of a specific publication due to changes in curriculum or research interests. To account for these challenges, the library unit specifically working on withdrawing and re-cataloging materials would compare withdraw and onsite storage lists with the library's active serial subscription and gift exchange lists and then notify subject selectors of any active subscription or gift titles impacted by the collection review.

Patron feedback. The process of gathering feedback from university faculty and staff concerning items proposed for withdrawal was not without its own challenges. Even with the implementation of the virtual review 
shelf that allowed for faster and greater discoverability of materials, some faculty members complained about the time commitment required to adequately review items proposed for withdrawal. As most faculty members are extremely busy with teaching and research responsibilities year-round, there really isn't an ideal time to ask for faculty feedback on a project of this size. Consequently, the response and participation from faculty varied greatly between departments and individuals. Faculty from some departments provided little to no feedback concerning items proposed for withdrawal while other departments and individuals generated large reconsideration lists.

Another reality of gathering faculty and staff feedback is that it is impossible to meet everyone's requests all of the time. However, we did try to honor as many faculty and staff requests as feasible, given our project limitations. We also responded respectfully and with as much information as possible when a particular request could not be granted. In many instances, we were able to negotiate a compromise on an acceptable solution. For example, one department did not want to withdraw any materials in a specific call number range and desired to keep these materials on the browsable shelves, regardless of past use or relevance to current curriculum or research. As a compromise, those items that would have been withdrawn in this call number range were instead moved to onsite storage.

Withdrawal policy. In hindsight, it may have been helpful to have an established "Withdrawal Policy" before beginning the project. Such a policy should be formally approved by faculty representatives and include a clear description of why collections must be reviewed periodically, along with the criteria and processes that will be used to make decisions.

There are several benefits to having such a policy. Ward (2015, p. 47) indicated that "some degree of potential opposition (both internal and external) may be deflected if the policy and the rationale behind it are easily accessible." Additionally, if frustrated accusations arise, the policy can be the target instead of the librarians who are carrying out the project. Policies can go even further in protecting librarians, for example: "If faculty members disagree with specific discard decisions, the Assistant Dean for Collection Development will consider those 
disagreements. The librarian who recommended discarding the disputed item will not be identified without his or her consent" (Auburn University, 2018).

\section{Conclusions}

For anyone considering a large-scale collection evaluation project, there are several key takeaways that should be considered throughout the planning and implementation process:

1. Develop and follow a withdrawal rationale and policy. Developing and following a clear justification for why and when materials should be removed from your library's collections can help guide evaluation efforts and avoid opposition. This is particularly valuable when patrons or other library personnel raise concerns with a collection evaluation project.

2. Involve all stakeholders early. Determine early on everyone who will be impacted by an evaluation project and bring them to the table. This includes both internal and external library users. It is better to take more time in the planning phase incorporating all stakeholder feedback than to have to make large adjustments after materials have been removed from the shelves.

3. Generate a generous timeline. Even with the most careful planning, a large-scale evaluation project is going to take more time than anticipated. Make sure to build in extra time in your proposed project timeline and be flexible to make necessary adjustments along the way.

4. Use analytic tools judiciously. Usage statistics and other metrics are valuable in making collection decisions; however, be aware of the limitations of the data you use in your evaluation and adjust your criteria accordingly. Consider incorporating multiple data points to provide a more holistic view of the value of your collections.

5. Develop solid evaluation criteria. As you consider the data available to assist in your evaluation, develop concrete criteria for determining what will remain in your collections and what will be withdrawn. Consider starting with a smaller sample of materials and test your criteria to see how this will likely impact your 
collections. Make necessary modifications for subsequent iterations before implementing your criteria widescale.

6. Create and use project management tools. Discover what will help you keep track of your progress and improve productivity of your evaluation project. This could be homegrown software unique to your institution or widely available project management tools.

7. Include patrons in the evaluation process. While completely crowdsourcing the evaluation process might not be feasible or advisable, it is important to involve your library patrons at some level of the evaluation process. This improves transparency and allows patrons the ability to voice their concerns and offer suggestions on how they would like to have these collections managed. 


\section{References}

Auburn University Libraries. (2018). Weeding/discard procedures. Retrieved from http://www.lib.auburn.edu/discard/

Baumbach, D. J., \& Miller, L. L. (2006). Less is more: A practical guide to weeding school library collections. Chicago, IL: American Library Association.

Busch, H., Nance, J., \& Teague, J. (2018). Collaborative weeding of an engineering collection: Two perspectives. Collection Management, 43(4), 276-282. https://doi.org/10.1080/01462679.2018.1479324

Crosetto, A., Kinner, L., \& Duhon, L. (2008). Assessment in a tight time frame: Using readily available data to evaluate your collection. Collection Management, 33(1-2), 29-50.

https://doi.org/10.1080/01462670802157908

DeMars, J. M., Roll, A., \& Phillips, K. (2019). Deep in the weeds: Faculty participation in a large-scale deselection project. Collection Management, 44(1), 21-34. https://doi.org/10.1080/01462679.2018.1544956

Dilevko, J., \& Gottlieb, L. (2003). Weed to achieve: A fundamental part of the public library mission? https://doi.org/10.1016/S1464-9055(02)00308-1

Dubicki, E. (2008). Weeding: Facing the fears. Collection Building, 27(4), 132-135. https://doi.org/10.1108/01604950810913689

Lugg, R. (2012). Data-driven deselection for monographs: A rules-based approach to weeding, storage, and shared print decisions. Insights, 25(2), 198-204. http://doi.org/10.1629/2048-7754.25.2.198

McAllister, A. D., \& Scherlen, A. (2017). Weeding with wisdom: Tuning deselection of print monographs in bookreliant disciplines. Collection Management, 42(2), 76-91. https://doi.org/10.1080/01462679.2017.1299657

McHale, C., Egger-Sider, F., Fluk, L., \& Ovadia, S. (2017). Weeding without walking: A mediated approach to listbased deselection. Collection Management, 42(2), 92-108. https://doi.org/10.1080/01462679.2017.1318729 
Metz, P., \& Gray, C. (2005). PERSPECTIVES ON ... : Public relations and library weeding. Journal of Academic Librarianship, 31(3), 273-279. Retrieved from https://www.lib.byu.edu/cgibin/remoteauth.pl?url=http://search.ebscohost.com/login.aspx?direct=true\&db=lxh\&AN=17319883\&site=eho st-live\&scope $=$ site

O’Neill, J. L. (2016). Weeding with ADDIE developing training for deselection at an academic library. Reference \& User Services Quarterly, 56(2), 108-115.

Soma, A. K., \& Sjoberg, L. M. (2010). More than just low-hanging fruit: A collaborative approach to weeding in academic libraries. Collection Management, 36(1), 17-28. https://doi.org/10.1080/01462679.2011.529241

Wagstaff, K. L., \& Liu, G. Z. (2018). Automated classification to improve the efficiency of weeding library collections. Journal of Academic Librarianship, 44(2), 238-247. https://doi.org/10.1016/j.acalib.2018.02.001

Ward, S. M. (2015). Rightsizing the academic library collection. Chicago, IL: American Library Association.

Zuber, P. (2012). Weeding the collection: An analysis of motivations, methods and metrics. Retrieved from https://pdfs.semanticscholar.org/c2e9/ec2238db83eac0c60bbe3ded9521ce439356.pdf 


\section{Appendix A}

\section{Library Coordination Team Membership for Weeding Project}

\begin{tabular}{|c|c|}
\hline Title/responsibility & Description \\
\hline $\begin{array}{l}\text { Associate University } \\
\text { Librarian for Collection } \\
\text { Development }\end{array}$ & Overall authority for the project; approved funding; mediated problems \\
\hline $\begin{array}{l}\text { Collection Development } \\
\text { Coordinator }\end{array}$ & $\begin{array}{l}\text { Assembled the team across several library divisions; convened and led the } \\
\text { meetings; provided follow-up on assignments; point person for questions or } \\
\text { concerns; mediated problems }\end{array}$ \\
\hline $\begin{array}{l}\text { Auxiliary Collections } \\
\text { Supervisor }\end{array}$ & $\begin{array}{l}\text { Supervised and managed the temporary storage of items that had been } \\
\text { removed from open stacks; changed the location record for items that had } \\
\text { moved from open stacks to the temporary storage location }\end{array}$ \\
\hline Stacks Manager & $\begin{array}{l}\text { Hired and maintained a cadre of student employees who tagged materials, } \\
\text { moved materials from the open stacks to the temporary storage location, } \\
\text { shifted and condensed materials after the primary evaluation period }\end{array}$ \\
\hline $\begin{array}{l}\text { Serials specialist from the } \\
\text { Cataloging Department }\end{array}$ & $\begin{array}{l}\text { Provided counsel on serials and serial records; performed analysis for more } \\
\text { robust serial catalog records }\end{array}$ \\
\hline $\begin{array}{l}\text { Science \& Engineering } \\
\text { Department representatives } \\
\text { (2) }\end{array}$ & $\begin{array}{l}\text { Represented the department and the librarians who would be creating } \\
\text { deselection lists and evaluating all the items in the open stacks; developing } \\
\text { reasonable time lines for project completion }\end{array}$ \\
\hline $\begin{array}{l}\text { LIT representative for } \\
\text { software support }\end{array}$ & $\begin{array}{l}\text { Interface for having easy workflow to change catalog records, especially } \\
\text { location changes; developed an in-house system to review all items } \\
\text { proposed for deselection, i.e. the "Virtual Review Shelf." }\end{array}$ \\
\hline Book Repair & $\begin{array}{l}\text { Brought in to establish a workflow for items identified in the project that } \\
\text { would need repair if they were going to be kept by the library }\end{array}$ \\
\hline $\begin{array}{l}\text { Cataloging Department } \\
\text { Chair }\end{array}$ & $\begin{array}{l}\text { Initially brought in to identify, approve and clear personnel to work on the } \\
\text { project especially near the end when items would need to be withdrawn } \\
\text { from the collection and the catalog record removed from public view. }\end{array}$ \\
\hline Assistant Building Manager & $\begin{array}{l}\text { Primary point of contact for any physical space issues and for removing the } \\
\text { existing shelving after they had been cleared of all materials }\end{array}$ \\
\hline $\begin{array}{l}\text { Serials specialist from } \\
\text { Material Acquisitions }\end{array}$ & $\begin{array}{l}\text { Serials became a special concern as librarians began working on the project } \\
\text { and a specialist in the area was invaluable to answer questions. They were } \\
\text { also included in the initial meetings so that they were aware of serial sets } \\
\text { that were selected for collection withdrawal to preemptively be prepared for } \\
\text { those materials. }\end{array}$ \\
\hline
\end{tabular}




\section{Appendix B}

Criteria Thresholds vs Discipline: Screening for Withdrawal ${ }^{1}$

\begin{tabular}{|c|c|c|c|c|c|}
\hline \multirow[b]{2}{*}{ Discipline } & \multirow{2}{*}{$\begin{array}{c}\text { AGE } \\
\text { Publication } \\
\text { Age, years }\end{array}$} & \multicolumn{2}{|c|}{ USAGE } & \multirow{2}{*}{$\begin{array}{c}\text { ACCESS } \\
\text { Min \# of } \\
\text { US } \\
\text { holdings }\end{array}$} & \multirow{2}{*}{$\begin{array}{c}\text { Boolean logic } \\
\text { Applied operators }\end{array}$} \\
\hline & & $\begin{array}{c}\text { \# Years } \\
\text { since last } \\
\text { use }\end{array}$ & $\begin{array}{c}\text { Min \# } \\
\text { of } \\
\text { uses }\end{array}$ & & \\
\hline $\begin{array}{l}\text { Biology/Plant \& Wildlife } \\
\text { Sciences }\end{array}$ & 15 & 15 & 1 & -- & Age OR Usage \\
\hline Chemical Engineering & 10 & 10 & 6 & 9 & Age AND Usage AND Access \\
\hline Chemistry/Biochemistry & 10 & 10 & 6 & 9 & Age AND Usage AND Access \\
\hline $\begin{array}{l}\text { Civil \& Environmental } \\
\text { Engineering }\end{array}$ & 10 & -- & 3 & 20 & Age AND Usage AND Access \\
\hline Communication Disorders & 20 & -- & --- & 15 & Age AND Access \\
\hline Communication Disorders & $11-19$ & - & 6 & 15 & Age AND Usage AND Access \\
\hline $\begin{array}{l}\text { Computer Science \& } \\
\text { Information Technology }\end{array}$ & 10 & 10 & 6 & 9 & Age AND Usage AND Access \\
\hline Construction Management & 10 & -- & 3 & 20 & Age AND Usage AND Access \\
\hline $\begin{array}{l}\text { Electrical/Computer } \\
\text { Engineering }\end{array}$ & 10 & 10 & 6 & 10 & Age AND Usage AND Access \\
\hline Exercise Science & 18 & 11 & 1 & -- & Age OR Usage \\
\hline $\begin{array}{l}\text { Experience Design } \\
\text { \& Management }\end{array}$ & 15 & 15 & 1 & -- & Age OR Usage \\
\hline Geography & 10 & - & 3 & 20 & Age AND Usage AND Access \\
\hline Geological Sciences & 10 & - & 3 & 20 & Age AND Usage AND Access \\
\hline Mathematics/Statistics & 10 & 10 & 6 & 9 & Age AND Usage AND Access \\
\hline $\begin{array}{l}\text { Mechanical/Manufacturing } \\
\text { Engineering }\end{array}$ & 10 & 10 & 6 & 10 & Age AND Usage AND Access \\
\hline $\begin{array}{l}\text { Microbiology \& Molecular } \\
\text { Biology }\end{array}$ & 10 & 10 & 6 & 9 & Age AND Usage AND Access \\
\hline Neuroscience & 18 & 11 & 1 & -- & Age OR Usage \\
\hline Nursing & 6 & 5 & 1 & 15 & Age AND Usage AND Access \\
\hline $\begin{array}{l}\text { Nutrition, Dietetics, \& Food } \\
\text { Science }\end{array}$ & 10 & 10 & 6 & 9 & Age AND Usage AND Access \\
\hline Physics \& Astronomy & 10 & 10 & 6 & 9 & Age AND Usage AND Access \\
\hline $\begin{array}{l}\text { Physiology \& } \\
\text { Developmental Biology }\end{array}$ & 18 & 11 & 1 & -- & Age OR Usage \\
\hline Public Health & 15 & 15 & 1 & -- & Age OR Usage \\
\hline
\end{tabular}

${ }^{1}$ Criteria looked for items whose publication age, years since last use, and US holdings thresholds were exceeded and minimum uses threshold was not exceeded. 


\section{Appendix C}

Criteria Thresholds vs Discipline: Screening for On-site Storage ${ }^{2}$

\begin{tabular}{|c|c|c|c|c|c|}
\hline \multirow[b]{2}{*}{ Discipline } & \multirow{2}{*}{\begin{tabular}{c}
\multicolumn{1}{c}{ AGE } \\
Publication \\
Age, years
\end{tabular}} & \multicolumn{2}{|c|}{ USAGE } & \multirow{2}{*}{$\begin{array}{c}\text { ACCES } \\
\text { S } \\
\text { Min \# of } \\
\text { US } \\
\text { Holdings }\end{array}$} & \multirow{2}{*}{\begin{tabular}{|c|} 
Boolean logic \\
Applied operators
\end{tabular}} \\
\hline & & $\begin{array}{l}\text { \# Years } \\
\text { since last } \\
\text { use }\end{array}$ & $\begin{array}{c}\text { Min \# } \\
\text { of Uses }\end{array}$ & & \\
\hline $\begin{array}{l}\text { Biology/Plant \& Wildlife } \\
\text { Sciences }\end{array}$ & 118 & -- & --- & 15 & Age OR Usage \\
\hline Chemical Engineering & 18 & 18 & -- & 10 & Age AND Usage AND Access \\
\hline Chemistry/Biochemistry & 18 & 18 & -- & 10 & Age AND Usage AND Access \\
\hline $\begin{array}{l}\text { Civil \& Environmental } \\
\text { Engineering }\end{array}$ & 10 & --- & 3 & 20 & Age AND Usage AND Access \\
\hline Communication Disorders & 20 & --- & -- & 15 & Age AND Access \\
\hline Communication Disorders & $11-19$ & --- & 6 & 15 & Age AND Usage AND Access \\
\hline $\begin{array}{l}\text { Computer Science \& } \\
\text { Information Technology }\end{array}$ & 18 & 18 & --- & 10 & Age AND Usage AND Access \\
\hline Construction Management & 10 & -- & 3 & 20 & Age AND Usage AND Access \\
\hline $\begin{array}{l}\text { Electrical/Computer } \\
\text { Engineering }\end{array}$ & 18 & 18 & --- & 10 & Age AND Usage AND Access \\
\hline Exercise Science & 77 & 10 & 1 & 10 & (Age OR Access) AND Usage \\
\hline $\begin{array}{l}\text { Experience Design } \\
\text { \& Management }\end{array}$ & 118 & --- & --- & 15 & Age OR Usage \\
\hline Geography & 10 & --- & 3 & 20 & Age AND Usage AND Access \\
\hline Geological Sciences & 10 & --- & 3 & 20 & Age AND Usage AND Access \\
\hline Mathematics/Statistics & 18 & 18 & -- & 10 & Age AND Usage AND Access \\
\hline $\begin{array}{l}\text { Mechanical/Manufacturing } \\
\text { Engineering }\end{array}$ & 18 & 18 & --- & 10 & Age AND Usage AND Access \\
\hline $\begin{array}{l}\text { Microbiology \& Molecular } \\
\text { Biology }\end{array}$ & 18 & 18 & --- & 10 & Age AND Usage AND Access \\
\hline Neuroscience & 77 & 10 & 1 & 10 & (Age OR Access) AND Usage \\
\hline Nursing & 6 & 5 & 1 & 15 & Age AND Usage AND Access \\
\hline $\begin{array}{l}\text { Nutrition, Dietetics, \& Food } \\
\text { Science }\end{array}$ & 18 & 18 & --- & 10 & Age AND Usage AND Access \\
\hline Physics \& Astronomy & 18 & 18 & --- & 10 & Age AND Usage AND Access \\
\hline $\begin{array}{l}\text { Physiology \& } \\
\text { Developmental Biology }\end{array}$ & 77 & 10 & 1 & 10 & (Age OR Access) AND Usage \\
\hline Public Health & 118 & --- & --- & 15 & Age OR Usage \\
\hline
\end{tabular}

${ }^{2}$ Criteria looked for items whose publication age and years since last use thresholds were exceeded and minimum uses and US holdings thresholds were not exceeded. 


\section{Appendix D}

\section{Human Judgment Factors}

\begin{tabular}{|l|l|}
$\begin{array}{l}\text { Evidence of use not captured } \\
\text { in screening data }\end{array}$ & $\begin{array}{l}\text { Check for stamps in book that indicate significant usage not captured in } \\
\text { Greenglass records }\end{array}$ \\
\hline $\begin{array}{l}\text { Check internal records for significant onsite use not captured in Greenglass } \\
\text { records }\end{array}$ & $\begin{array}{l}\text { Note that internal usage of reference items is tracked well; consider keeping key } \\
\text { reference books }\end{array}$ \\
\hline Availability & $\begin{array}{l}\text { Check holdings in local (statewide) libraries for books meeting withdraw criteria; } \\
\text { consider onsite storage if no such holdings }\end{array}$ \\
\hline Series & Consider preserving series, even if some volumes fit withdraw criteria \\
\hline Multiple editions & $\begin{array}{l}\text { Consider keeping newest edition, even if older editions have more usage; } \\
\text { consider keeping multiple editions for historical reference if substantially different }\end{array}$ \\
\hline
\end{tabular}

\begin{tabular}{|c|c|}
\hline \multirow[t]{2}{*}{ Duplicates (identical content) } & Check usage and consider keeping multiple copies on shelf if highly used \\
\hline & Assess condition of each copy and withdraw worst \\
\hline Foreign language & $\begin{array}{l}\text { Consider preserving (in onsite storage) foreign language science books with } \\
\text { minimal recent use }\end{array}$ \\
\hline \multirow[t]{2}{*}{ Historical value } & $\begin{array}{l}\text { Look for histories of a subject and notable biographies in a subject area and } \\
\text { consider keeping representative works on shelves; consider placing alternate/less } \\
\text { notable works in onsite storage }\end{array}$ \\
\hline & $\begin{array}{l}\text { Check for other value such as marginalia/signatures of notable persons (annotate } \\
\text { records so these features are discoverable) }\end{array}$ \\
\hline \multirow[t]{6}{*}{ Breadth of coverage } & $\begin{array}{l}\text { Consider keeping resources supporting active teaching or research areas } \\
\text { regardless of indications of use, if subject is not otherwise well covered }\end{array}$ \\
\hline & $\begin{array}{l}\text { Identify seminal works/texts and consider keeping regardless of recent use; } \\
\text { consider keeping all items that are representative of the body of theory in a } \\
\text { subject, including items officially published by practitioner associations as best } \\
\text { practices (e.g. nursing practice) }\end{array}$ \\
\hline & $\begin{array}{l}\text { Check to see if publications marked for withdrawal are the most recent } \\
\text { publications on the subject and, if so, consider keeping representative copies }\end{array}$ \\
\hline & $\begin{array}{l}\text { Consider keeping materials that provide a unique treatment of a subject, or if the } \\
\text { subject itself is unique and interesting }\end{array}$ \\
\hline & Consider keeping materials with artistic value/works of art \\
\hline & $\begin{array}{l}\text { Keep materials in subject areas that faculty members have specifically requested } \\
\text { to keep. }\end{array}$ \\
\hline Community interest & $\begin{array}{l}\text { Consider keeping items of interest to community: e.g., author or content } \\
\text { connection to institution or institutional sponsor (e.g., Church); publication by } \\
\text { institution; connection to or subject matter about the institution's state of residence }\end{array}$ \\
\hline
\end{tabular}

